\title{
Making time for partnership
}

\section{John Launer}

Almost every doctor will recognise the following (fictionalised) story as one that is wearily common. Tom is aged 35 . In the past year he has attended accident and emergency departments in six different cities, each time with abdominal pain. Sometimes he has presented with other symptoms, including blood and mucus in his stools, but sometimes he just has the pain. Each time he attends, a doctor carefully examines him, orders a battery of blood tests and imaging, decides there is nothing acute about his problem, and sends him on his way, with or without an immediate supply of medication. Now and again, depending on the picture of symptoms that day, the doctor who sees Tom explains that he probably has inflammatory bowel disease, and says a few brief words about what this means. Whether or not that happens, everyone in the accident and emergency department always emphasises how important it is for him to see his GP and get things sorted out. Tom assures them he will do so, but he also knows that two things stand in his way. Firstly, his job requires him to move from one city to another every few weeks. Secondly, he remembers how his father also had inflammatory bowel disease, and how doctors looked after it rather poorly.

The medical notes in every hospital Tom has attended include copious details of his symptoms, past history, and signs and investigations (in other words, the 'contents' of his problem), but little or nothing about his job or his memories of his father (in other words, the 'contexts' of the problem.). Few of the nurses or doctors who have seen him have made the time to elicit this part of the story from Tom, or had sufficient patience to put him at his ease so that he feels able to disclose it. The one or two professionals who have done so have not considered it was their proper role to engage fully with this aspect of his problem. They are, after all, providing emergency care only.

\section{HABITUAL ATTENDERS}

If you haven't come across Tom with inflammatory bowel disease, you have

Correspondence to Dr John Launer, London Deanery, London Department of Postgraduate Medical Education, Stewart House, 32 Russell Square, London WC1B 5DN, UK; jlauner@londondeanery.ac.uk almost certainly encountered Dick with gout and migraines or Harriet with asthma, or a hundred other people with chronic conditions who, for whatever reason, habitually attend acute care centres of one kind or another without ever managing to connect with long term medical care. And if you work in the community, you will have met such people in GP surgeries where they turn up every time without an appointment and never come back for booked consultations. What can be done in cases like Tom's, or Dick's or Harriet's, or the countless thousands of others like them who come in and out of the revolving doors of acute care when really they need a one way ticket to continuous, long term care?

What Tom needs, of course, is a meaningful and reasonably long conversation about his bowel problem. Someone-anyone-needs to engage with him about his job circumstances and family background. They need to talk with him intelligently about why he should take a radically different approach to his illness, and help him think through how he might do this. And they need to do it now, at this very moment, right here in the accident and emergency department, rather than depending on someone else to do it at a later date. But of course we all know this isn't going to happen, either now or at his next visit elsewhere, or the one after that. The likelihood is that, at the very least, Tom will sustain years of damage to his quality of life. If he is unlucky he may also end up with a preventable and possibly fatal abdominal catastrophe, or cancer.

\section{TAKING CHARGE}

There is a lot of talk nowadays about partnership with patients, and of encouraging them to take charge of their chronic conditions and see these as a responsibility that they should take on themselves, while working alongside professional carers. The recently elected coalition government in the UK regards this as such an important principle that they have placed it almost at the centre of their health service policy, not to mention their hopes of containing expenditure within the public sector. However, as we have seen in Tom's case, there's many a slip twixt cup and lip. The sad fact of the matter is that we may be expecting patients to enter into partnership with us without adjusting our own habits or systems to join into that partnership ourselves.

If we are to transform the notion of partnership from a rhetorical slogan into anything that has meaning, we need to learn the lesson from cases like Tom's. We need, first of all, to recognise that partnership is created not in policy documents or by high level directives, but through seizing the moment each and every time that a Tom, Dick or Harriet comes our way. It means reorienting ourselves from taking purely biomedical histories to taking biographical ones as well. It involves each of us-not just GPs-acquiring the conversational skills to engage with the kinds of issues that prevent a man like Tom looking after himself, as well as learning the skills to motivate him to behave in a different way. It requires an awareness that lives are improved, or even saved, not just by the careful physical examination or the correct diagnosis, but by the quality of the conversations around them. If the truth be told, these are not conversations that necessarily call for inordinate amounts of time. Very often, what they really need is empathy, professionalism, presence, and a belief that the medical task goes beyond mere proceduralism.

\section{SHIFTING CARE}

In the next few years we will no doubt see a diversion of resources in the health service, not just in the UK but everywhere, into schemes and programmes launched under the banner of 'partnership with patients'. There will be a serious and concerted attempt to shift care from doctor-patient consultations towards other forms of activity such as educational groups for patients, and the widespread use of self-help organisations and community websites. Some of these schemes may be barely disguised attempts to cut costs, but others are likely to be well conceived, at least at the level of systems design and educational input. A number of these partnership schemes may stand a genuine chance of improving the quality of patients' lives (something for which there is good evidence). They may even make a significant difference to disease outcomes (something that remains largely unproven but is reasonable to expect). In a few cases they may actually reduce costs, although, paradoxically, they may of course increase these costs as patients become more aware of treatments they could ask for. 
However, unless we start by offering skilled and engaged conversations at the very moment they are needed, the benefits in all these areas are likely to be small. We cannot expect patients to become partners unless we are willing to offer partnership from the very first moment, whenever and wherever we see them.

Published Online First 5 August 2010

Postgrad Med J 2010;86:569-570. doi:10.1136/pgmj.2010.106443

Competing interests None.

Provenance and peer review Commissioned; not externally peer reviewed.

\section{Correction}

Edmund M Godfrey, Simon M Rushbrook, Nicholas R Carrol. Endoscopic ultrasound: a review of current diagnostic and therapeutic applications. Postgrad Med J 2010;86:346-353.

The third author's name in this paper was misspelt; it should be Carroll.

Postgrad Med J 2010:86:570. doi:10.1136/pgmj.2009.096065corr1 